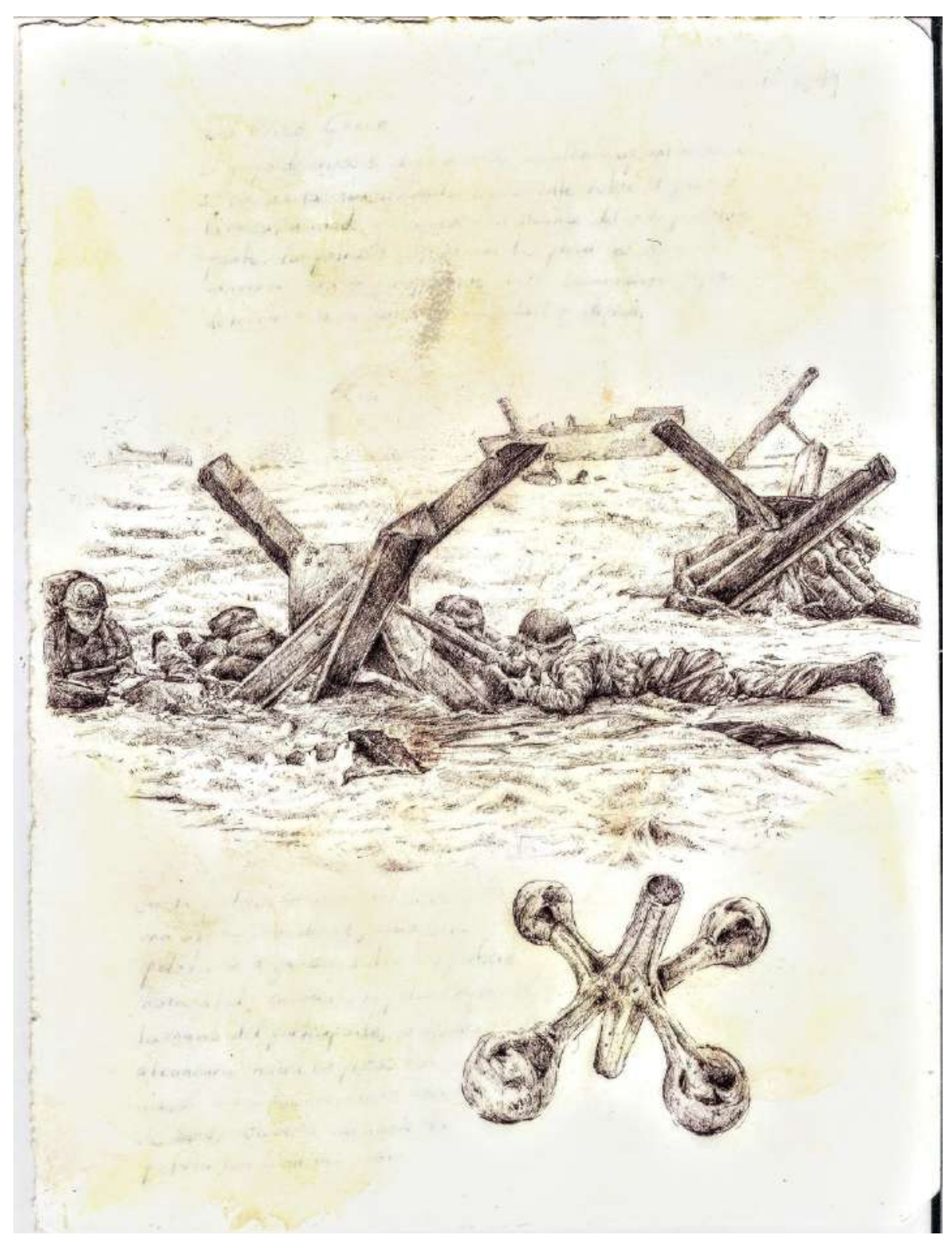

Sebastián Zea Quintero

Sin título

De la serie Del juego y el hombre Lápiz sobre papel 2017 Medellín 


\title{
El peronismo y la ciudad. Competencia y articulación en las estrategias electorales del Partido Justicialista en La Plata, Argentina (2015-2019)*
}

\author{
Martín Retamozo (Argentina)** \\ Cristóbal Dell'Unti (Argentina) ${ }^{* * *}$
}

\section{Resumen}

El análisis de la organización interna del peronismo resulta un tema de discusión muy concurrido en los estudios de partidos políticos argentinos. De las diferentes matrices analíticas que participan de este diálogo, los análisis que se focalizan en la dimensión municipal han señalado fenómenos significativos para comprender las lógicas de interacción del universo de grupos que componen esta fuerza. Este artículo se propone aportar evidencia para comprender la dinámica política del peronismo en la ciudad de La Plata, Argentina, enfocándose en los procesos electorales entre 2015 y 2019, cuando esta fuerza política fue oposición en los ámbitos local, provincial y nacional. El estudio muestra cómo los actores políticos locales del peronismo definen sus tácticas en estructuras de oportunidades electorales específicas a partir de los recursos disponibles: candidaturas competitivas y capacidad de articulación con agrupaciones de base. Esto muestra una lógica de «movimiento partidario» que el peronismo platense activa y que le ha permitido tener un recambio de élites partidarias y una reconversión en su relación con el electorado.

\section{Palabra clave}

Partidos Políticos; Elecciones Subnacionales; Política Local; Movimiento Partidario; Estructura de Oportunidades Electorales; Peronismo.

\footnotetext{
* Este artículo es resultado del proyecto investigación El Estado en movimiento y los movimientos en el Estado, (2016-2019), con el apoyo de la Universidad Nacional de La Plata y del Consejo Nacional de Investigaciones Científicas y Técnicas (Conicet).

${ }^{* *}$ Profesor de Filosofía. Magíster en Ciencias Sociales. Doctor en Ciencias Sociales. Profesor e investigador del Instituto de Investigaciones en Humanidades y Ciencias Sociales, Facultad de Humanidades y Ciencias de la Educación, Universidad Nacional de La Plata, y del Consejo Nacional de Investigaciones Científicas y Técnicas (Conicet), Argentina. Correo electrónico: martin.retamozo@, gmail.com - Orcid: 0000-0001-8778-7667 - Google Scholar: https://scholar.google.com/citations?hl= es\&user=zi3gViEAAAAJ

*** Profesor en Filosofía. Magíster en Ciencias Sociales y Políticas. Doctor en Ciencias Sociales. Profesor e investigador del Instituto de Investigaciones en Humanidades y Ciencias Sociales, Facultad de Humanidades y Ciencias de la Educación, Universidad Nacional de La Plata, y del Consejo Nacional de Investigaciones Científicas y Técnicas (Conicet), Argentina. Correo electrónico: cristobal.delunti@ gmail.com - Orcid: 0000-0002-1442-7182
} 
Fecha de recepción: octubre de 2019

- $\quad$ Fecha de aprobación: abril de 2020

Cómo citar este artículo

Retamozo, Martín y Dell'Unti, Cristóbal. (2020). El peronismo y la ciudad. Competencia y articulación en las estrategias electorales del Partido Justicialista en La Plata, Argentina (2015-2019). Estudios Políticos (Universidad de Antioquia), 58. pp. 233-261. DOI: 10.17533/udea.espo.n58a11

\title{
Peronism and the City. Competence and Articulation in the Electoral Strategies of the Justicialist Party in La Plata City, Argentina (2015-2019)
}

\begin{abstract}
The analysis of the internal organization of Peronism is a very popular topic of discussion in the studies of Argentinean political parties. From the different analytical matrices that participate in this dialogue, the analyses focused on the municipal dimension have indicated important phenomena to understand the logic of interaction of the several groups that compose this force. This article aims to provide evidence to understand the political dynamics of Peronism in the city of La Plata (Argentina) by focusing on the electoral processes between 2015 and 2019, when this political force was opposition at the local, provincial, and national levels. The study shows how the local political actors of Peronism define their tactics in structures of specific electoral opportunities from the available resources: competitive candidacies and capacity for articulation with grassroots groups. Accordingly, the «platense» Peronism displays a logic of «partisan movement» which has allowed it to have a turnover of party elites and a reconversion in its relationship with the electorate.
\end{abstract}

\section{Keywords}

Political Parties; Subnational Elections; Local Politics; Party Movement; Electoral Opportunity Structure; Peronism. 
El peronismo y la ciudad. Competencia y articulación en las estrategias electorales...

\section{Introducción}

Parafraseando a John William Cooke, ${ }^{1}$ el peronismo es el hecho maldito de los estudios políticos en-sobre Argentina. Elusivo, persistente y anfibio, el peronismo tensiona las miradas que pretenden encasillarlo en matrices pre-establecidas, en perspectivas legaliformes o subsumirlo en tendencias generales. La preocupación por estudiar su anatomía, sus características como fuerza política y su relación con el régimen de representación, por supuesto, no es nueva. En cierto modo, la sociología política argentina se generó en torno a preguntas que tenían al peronismo como protagonista, incluso en tiempos en que estaba proscripto. ${ }^{2}$ Obras clásicas como las de Gino Germani (1965) y Miguel Murmis y Juan Carlos Portantiero (1969), por ejemplo, centraron la discusión en la relación entre clases sociales, formas de movilización, organizaciones y liderazgo. Esta cuestión atravesó tanto a los estudios en torno al concepto de populismo (Di Tella, 1973, Laclau, 1978) como a aquellos enfocados, luego, en los procesos identitarios (James, 1990; Torre, 1999; Martuccelli y Svampa, 1997; Altamirano, 2001; Barry, 2009), que indagaron en la configuración del Movimiento Nacional Justicialista.

La transición a la democracia en Argentina incluyó una novedad: la derrota electoral del peronismo en 1983. En consecuencia, emergieron preocupaciones que fueron objetivadas desde las ciencias políticas: por un lado, el tema de la partidización, las reglas internas y su inserción en el sistema democrático (Aboy Carlés, 2001; Mustapic, 2002; Mackinnon, 2002; Ollier, 2010); por otro lado, la relación del peronismo con el problema de la adaptación a los cambios de las variables ambientales, fundamentalmente en la década de 1990 y su reconfiguración como fuerza política (Novaro, 1999; Levitsky, 2005). Con la aparición en la escena política de Néstor Kirchner, tras la crisis de 2001, esta agenda agregó como nuevo tema el problema de la integración de las novedosas organizaciones del campo popular (Pérez y Natalucci, 2012; Schuttenberg, 2014; Casullo, 2019), la reconsideración de la función y discursos de los liderazgos nacionales (Montero, 2012), y el nuevo esquema de ejercicio del poder, tanto en el ámbito nacional como en la agenda internacional.

\footnotetext{
${ }^{1}$ Diputado durante el primer gobierno peronista y figura destacada de la «resistencia peronista» luego del golpe de Estado de 1955. Su frase «el peronismo es el hecho maldito del país burgués» es un lugar común en la política argentina.

${ }^{2}$ Previamente, el peronismo como problema político fue abordado teóricamente en distintas revistas como Contorno, Pasado y Presente, entre otras.
} 
La mirada subnacional del fenómeno comenzó a cobrar relevancia y desarrollo en los últimos años. El debate se estructuró sobre la organización peronista a escala municipal o provincial, desde los orígenes del peronismo y su despliegue en el tiempo. Las denominadas investigaciones extracéntricas (Tcach, 2002), referidas al primer peronismo revisaron los modos en que se articuló la organización en el ámbito provincial (Macor y Tcach, 2003; 2013; Aelo, 2006; Rein, 2008). Por su parte, los estudios subnacionales que se enfocan en la actualidad abarcan las dinámicas políticas en los ámbitos provincial y municipal, contribuyendo a identificar particularidades invisibles a la mirada centrada en lo nacional (Eryszewicz, 2015; Lenarduzzi, 2012; Ferrari, 2016).

Este artículo se enmarca en las investigaciones subnacionales ${ }^{3}$ y se propone aportar a la comprensión de la dinámica política del peronismo en el ámbito local del distrito de La Plata. ${ }^{4}$ Para ello se reconstruyeron las estrategias de esta fuerza política en dos eventos electorales y se exponen las variables que explican las tácticas de los agrupamientos o polos organizativos entre 2017 y 2019. El estudio muestra que la interacción entre tácticas autónomaslocales, estructura de oportunidades electorales y vetos de las élites partidarias

[236] nacionales configura una forma de «movilización partidaria» del peronismo en tiempos electorales.

El enfoque en la ciudad de La Plata es particularmente relevante por los siguientes motivos: primero, por tratarse de una ciudad importante, capital de la Provincia de Buenos Aires, donde el peso de las tres instancias de gobierno tiene particular incidencia; segundo, porque sus características, ligadas, en buena medida, al empleo público provincial y a la universidad, y a la historia del peronismo — vale recordar que fue denominada «Ciudad Eva Perón»— originaron una multiplicidad de organizaciones de base sindicales, territoriales, estudiantiles, culturales, entre otros- inscriptas en el peronismo; tercero, porque fue escenario de un interesante proceso de competencia interna y reemplazo de las élites de conducción local.

\footnotetext{
${ }^{3}$ Para un panorama actualizado de la investigación politológica sobre el nivel subnacional en Argentina, véase Sebastián Mauro, Victoria Ortiz y Martín Paratz (2017).

${ }^{4}$ Distrito capital de la Provincia de Buenos Aires y única sección electoral que contiene un solo municipio. La ciudad de La Plata es al mismo tiempo la octava sección electoral de la Provincia y el municipio de cabecera.
} 
El peronismo y la ciudad. Competencia y articulación en las estrategias electorales...

\section{Coordenadas teórico-metodológicas para el estudio de estrategias locales}

En función de poder abordar el estudio de caso y atendiendo a la complejidad que implica el estudio de las mediaciones locales agrupaciones - del peronismo en el distrito, fue necesario tomar algunas decisiones de orden metodológico. La cuestión central es el desafío que supone poder integrar en una misma lectura la multiplicidad de fenómenos que el peronismo genera en el ámbito local. A diferencia de una visión estereotipada sobre el peronismo —y el populismo en general— que lo define como un tipo de movimiento top-down y sin mediaciones organizativas, esta investigación encuentra relevante reparar tanto en la multiplicidad como en la heterogeneidad y en la capacidad de agencia de actores que tienen al peronismo como identidad común y, a su vez, distintas relaciones con las élites partidarias nacionales o provinciales. Esto, que epistemológicamente supone un desplazamiento de la perspectiva analítica, implica discutir $-\mathrm{O}$ abandonar - el supuesto de que todo evento local se sintetiza - y explicapor las acciones de la élite nacional o provincial. Por el contrario, el supuesto que estructura esta investigación es que entre actores de distintos ámbitos las relaciones que se despliegan son «negociaciones asimétricas», la cuales no tienen ni un resultado prefijado, ni un carácter de «imposición» de tipo vertical descendente. En este sentido, la propuesta de caracterización general del peronismo se encuentra más en dialogo con la idea de «sistema no del todo cerrado» (Casullo, 2015), en el cual se (re)producen permanentemente nuevas representaciones vinculadas a la capacidad de incorporación de demandas.

Analizar el peronismo de «abajo hacia arriba» requiere proponer criterios que ordenen la multiplicidad de datos. Dos criterios son centrales: uno referido al estrato analítico, centrado en los polos agrupacionales o agrupamientos consolidados. Con estas denominaciones se hace referencia a aquellos modos de organización internas que se presentan a elecciones generales —locales - y que, estructuralmente, son alianzas internas entre agrupaciones de base. Se presenta este concepto puesto que la noción de «alianzas» refiere a los fenómenos de articulación entre un partido o un sector — fracción- del partido con uno o varios actores de otras identidades políticas (Sartori, 1994). Al respecto, las articulaciones internas de la multiplicidad y heterogeneidad de grupos de base existentes en el peronismo platense exigen una precisión de esta noción. 
El segundo criterio es analizar estos polos en función de los factores que condicionan sus acciones. Tres de ellos son de particular interés:

a) El primer factor es la acción de las élites extralocales fundamentalmente nacionales - en las definiciones locales. Esto, en parte, porque las élites establecen una expectativa electoral propia de tracción de votos, teniendo en cuenta que las elecciones analizadas son simultáneas. En efecto, un candidato con chances en el ámbito nacional o provincial genera incentivos para que los grupos locales disputen lugares en la boleta, aun cediendo protagonismo en las listas, ${ }^{5}$ mientras que un candidato con menor caudal electoral mejora el juego de los actores locales para poner condiciones a su inclusión en la misma o amenazar con una salida; además, porque las élites —nacionales y provinciales — pueden oficiar de jugadores de veto a determinadas candidaturas o tácticas a partir de la normativa partidaria o el ejercicio de reglas informales. No obstante, los actores locales pueden negociar con las élites cuando poseen candidatos competitivos o amenazando con «salida» hacia otra fuerza política. Nótese que este factor de condicionamiento opera a posteriori de la postulación del candidato, por lo que podría entenderse como una variante de los «mecanismos competitivos» (Freidenberg, 2006) que mencionan las diversas corrientes analíticas que estudian la correlación entre elección de candidatos y democracia interna.

b) El segundo factor es el campo pluriorganizacional del peronismo platense. Es posible identificar la existencia de una multiplicidad heterogénea de organizaciones peronistas: sindicatos, unidades básicas, agrupaciones culturales, estudiantiles, territoriales o barriales, entre otros, que forman parte del campo del peronismo en su faz movimientista y que surgen con sustanciales grados de autonomía y variedad de lazos con las fuerzas existentes. Este aspecto es clave para comprender al peronismo, en general, y al platense, en particular, y la posibilidad de emergencia de experiencias colectivas que se inscriben en el peronismo sin ser impulsadas por la estructura partidaria.

En este sentido, un polo organizacional —alianza interna - es un nucleamiento de segundo grado que logra estabilizar espacios con capacidad

\footnotetext{
${ }^{5}$ Cabe recordar que el sistema de votación en Argentina es con boleta partidaria, es decir, cada partido presenta una boleta en la que aparecen los candidatos nacionales, provinciales y locales del partido. Es posible «cortar boleta», o sea, optar por diferentes partidos para cada uno de los tramos electivos, pero existe un desincentivo a esta práctica, por lo que ir en la boleta con un candidato competitivo es una ventaja en el ámbito local.
} 
El peronismo y la ciudad. Competencia y articulación en las estrategias electorales...

de agencia. La modalidad interna que adoptan estas alianzas puede ser de diversos tipos: centralizada sobre un candidato que opera como punto de articulación; colectivas-horizontales entre agrupaciones que conforman el espacio de articulación al que luego se le añade un candidato; mixtas, en la que candidatos y agrupaciones tienen un peso similar. La observancia de este condicionamiento es particularmente relevante en función de un diálogo con aquellas investigaciones que abordan las trayectorias de los intendentes en función de variables exógenas al municipio. Propuestas muy interesantes como el concepto de ambición estática (Varetto y Rotman, 2017) pueden encontrar otras explicaciones con la inclusión de variables endógenas municipales, como la articulación de los sectores internos.

c) El tercer factor es el tipo de interpelación sobre el electorado, cuyas demandas ciudadanas los diferentes actores eligen identificar y representar. Esto es clave en el registro táctico que cada agrupamiento utiliza en sus modos de intervención pública y en la modulación discursiva de la campaña. Las fluctuaciones que estas interpelaciones presentan a lo largo del tiempo reflejan las relaciones con las élites extralocales y los núcleos de sentido que estas estrategias locales quieren explotar. Si como mostró Julieta Lenarduzzi (2012) el ethos de la renovación política que operó en muchas de las campañas políticas municipales — entre ellas la de La Plata— permitió a los candidatos buscar formas de recomposición de un lazo de representatividad, la observancia de otras modulaciones permite profundizar una comprensión de lo que implica una territorialización (Calvo y Escolar, 2005), no solo de las preferencias electorales sino también de las ofertas. ${ }^{6}$

Para poder abordar un estudio de caso como el aquí propuesto, se construyeron algunos conceptos y categorías en diálogo con la literatura especializada. Así, en primer lugar, se definió la estrategia electoral como la resultante de la interacción de las tácticas de los actores, las cuales son estipuladas en función de los objetivos específicos que cada uno determina. Atendiendo la amplia discusión sobre los objetivos políticos de los actores, se retoma la advertencia de Robert Michels (1979) sobre la variación de estos con su conocida ley de hierro de las oligarquías partidarias, la cual derivó, entre otros análisis, en la afirmación del estudio de Angelo Panebianco (1990, p. 30) sobre el prejuicio teleológico. Estas reflexiones permiten sostener que no existen objetivos predeterminados al devenir de las acciones de los agentes.

${ }^{6}$ Para profundizar sobre diferentes derivaciones de la territorialización de las preferencias electorales en Argentina, véase, Leandro Eryszewicz (2015). 
Estos objetivos exceden el mero hecho de ganar las elecciones $u$ obtener la mayor cantidad de votos posible, en tanto también incluyen afianzar la identidad colectiva, defender ciertos criterios ideológicos o construir identificaciones particulares. La relación entre estrategias y tácticas no es solo una cuestión de escalas, sino también de variables que entran en juego al momento de la acción concreta. Las tácticas son condicionadas por el conjunto de reglas formales —al tomar las elecciones, en este caso, adquieren relevancia la normativa electoral y el estatuto partidario- y ciertas reglas informales cuya reconstrucción es recursiva. La existencia de reglas informales al interior del peronismo, que operan sobre la escasa legitimidad de las reglas formales, fue estudiada a fondo por Steven Levitsky (2005) y también dan cuenta de estas Ernesto Calvo (2013) y Juan Carlos Torre (1999). Una discusión interesante que excede los límites de este trabajo es la relación entre dichas prácticas y los efectos de la renovación política (Ferrari, 2016).

El otro factor que incide en el campo de posibilidad de una táctica es el aspecto identitario que funciona como un horizonte de posibilidades. En el caso estudiado conviven diferentes dimensiones de identificación que son actualizadas en cada momento por los actores, que habilitan márgenes de acción y que sirven también para legitimar públicamente esas decisiones.

Estas dimensiones identitarias tienen disímiles grados de abstracción indeterminación- y van desde el «movimiento nacional y popular», el «peronismo» y el «kirchnerismo», con sus rupturas y continuidades.

La categoría de táctica electoral permite observar la opción que despliegan los actores a partir de los medios disponibles en el marco de una coyuntura, a fin de alcanzar sus objetivos políticos. En este sentido, aquello que cabe dentro de esta categoría es el conjunto de variables que los actores o agrupaciones atienden al momento de definir el modo en el que se conducirán en los procesos eleccionarios, dada la información con la que disponen, sus expectativas, las reglas que estructuran el juego democrático y la acción de los competidores y adversarios.

Las definiciones tácticas de una agrupación local se producen en el marco de una evaluación del contexto o la coyuntura en la que estas se encuentran inmersas. Esto implica que existe una dimensión externa a las decisiones e independiente de los actores, pero que impacta en estos a partir de los enmarcados que realizan (McAdam, Tarrow y Tilly, 2005, p. 49). En el 
El peronismo y la ciudad. Competencia y articulación en las estrategias electorales...

estudio de los actores movilizados es muy utilizado el concepto de estructura de las oportunidades políticas (Tarrow, 1997, p. 49). En esta investigación se usa el concepto de estructura de oportunidades electorales con el objetivo, por un lado, de acotar el alcance del concepto a los eventos electorales y a los actores locales como agentes de la acción; y a su vez, pretende amalgamar recursos que son «internos» al grupo, fundamentalmente, la capacidad de articular y conducir un marco de alianzas locales y contar con un candidato competitivo. Esto enriquece el concepto porque permite incluir los procesos que marcan el contexto de la acción y recursos que no dependen exclusivamente de la decisión de los actores, ambos mediados por el enmarcado que hacen de los factores «objetivos» internos y externos.

En este sentido, la táctica de los actores depende de dos recursos políticos principales: contar con un candidato con proyección electoral una figura atractiva y atrayente para el electorado- para el cargo al que se pretenda competir y tener la capacidad de concretar un marco de alianzas con otros sectores para conseguir volumen de acción. Estos dos recursos parecen ser centrales al momento de comprender el conjunto de decisiones y problemas que les son propios a los actores. Contar con un candidato visible y competitivo es un proceso que se verifica por el ejercicio del liderazgo — apariciones en medios de comunicación, actos y mítines- y se valida retrospectivamente mediante los resultados electorales. Por su parte, para observar el marco de alianzas en coyunturas electorales es posible recurrir a diferentes observables. Otra posibilidad es analizar las «solicitadas», publicaciones en diarios que contienen una consigna y un conjunto de formas que avalan dicho mensaje — pueden ser de personas o de agrupaciones-. En este caso $-y$ por límites de extensión — se focaliza el análisis de las boletas electorales locales, en tanto visibilizan el peso específico que esas agrupaciones de base tienen en el marco de alianzas y el tipo de lógica que funciona en dicha construcción.

La estrategia metodológica para indagar la dinámica del campo político peronista fue seguir los eventos electorales entre 2017 y 2019. Los datos que nutren la investigación fueron construidos a partir de tres técnicas: análisis del discurso — prensa local, publicidad de campaña—, entrevistas a referentes, composición de las listas y registro de los resultados electorales. Se utilizaron fuentes para el contexto, como la normativa electoral y las normativas internas de los espacios políticos. 


\section{Antecedentes del peronismo en la ciudad de La Plata (2001-2015)}

Las elecciones legislativas de 2001 y la posterior crisis de diciembre de ese año marcaron un punto de inflexión en el régimen social de acumulación y el régimen político argentino (Mustapic, 2005). Para el peronismo platense se abrió allí un proceso de disputa interna que se desarrolló, incluso, hasta las elecciones aquí estudiadas, por eso lo ubicamos como coyuntura iniciática que marca la temporalidad de este estudio. En los comicios de 2001, el peronismo fue la única fuerza que pudo superar el denominado «voto bronca» ${ }^{7}$ y a la vez comenzó el declive de la hegemonía de Julio Alak, que desde 1991 había estado al frente del Ejecutivo municipal y de la presidencia del Partido Justicialista. La merma en la cantidad de $\operatorname{votos}^{8}$ y la fuerte crisis de representación que impactó en todo el sistema político configuró una nueva estructura de oportunidades que fue aprovechada por otros actores del peronismo para animarse a disputar la conducción. En efecto, actores subordinados del partido y con menos recursos encontraron incentivos para la disputa interna. Distintos factores coadyuvaron a consolidar esta ventana: la asunción de Néstor Kirchner a la Presidencia de la Nación en 2003, con una fuerte disputa contra las corrientes peronistas asociadas al expresidente Carlos Menem —entre ellas, el mismo Alak—; una fragmentación y crisis interna de las fuerzas no peronistas; y un contexto social que exigía un recambio dirigencial en todos los ámbitos.

El primer grupo que se animó a romper y presentarse en las elecciones de 2003 con otra boleta electoral, es decir, por fuera de la estrategia del peronismo, se autodenominó Frente Renovador Platense (FRP). ${ }^{9}$ Esta organización contaba con recursos relevantes: un candidato al Ejecutivo

\footnotetext{
${ }^{7}$ En las elecciones de 2001 la particularidad de los resultados llevó a la prensa a denominar como «voto bronca» — o voto de protesta - a aquellos sufragios que expresaron malestar con la dirigencia política —incluía el voto nulo, más el voto en blanco-. En La Plata este tipo de voto alcanzó $26 \%$ de los sufragios en 2001, solo superado por la lista de candidatos del Partido Justicialista (PJ). En el ámbito nacional ese «voto bronca» alcanzó 22\% (Escolar, Calvo, Calcagno y Minvielle, 2002; Vilas, 2004).

${ }^{8}$ En 1999 el peronismo obtuvo 52,92\% de los votos válidos (167 429), mientras que en 2001 fue de 40,36\% (93 047). El punto central de esta comparación es la escasa cantidad de votos más que el porcentaje (Argentina.gob.ar, s. f.; y Junta Electoral, s. f.).

${ }^{9}$ El uso de «renovación» como denominación en el peronismo ha sido una constante y hace alusión a grupos que buscan reemplazar a las élites consolidadas en los ámbitos municipal, provincial o nacional. Para el caso de los renovadores en el ámbito nacional y en la Provincia de Buenos Aires en 1985, véase Martina Garategaray, 2013), y para el caso de los intendentes de la Provincia de Buenos Aires en 2013, véase María Esperanza Casullo y Santiago Rodríguez, 2015, junio 4).
} 
El peronismo y la ciudad. Competencia y articulación en las estrategias electorales...

municipal con una buena imagen pública; una alta capacidad de articulación con otros grupos locales — peronistas y no peronistas-, una buena relación con el principal medio de comunicación local —el diario El Día- y un formato de acción política de cercanía o proximidad (Annunziata, 2013). El FRP se convirtió en un espacio que les permitía una reconversión o una potencialidad con la que no contaban hasta ese momento, ambas cosas pasibles de ser observadas en las listas de candidatos a concejales, las cuales mostraban una amplitud en la distribución de lugares hacia distintas expresiones políticas con centro en el peronismo platense, pero incluyendo a otros sectores aliados. ${ }^{10}$

La corriente política impulsada por Néstor Kirchner ${ }^{11}$ —en tanto este sector no contaba con referentes propios significativos en La Plata- fue aprovechada por el FRP, que se configuró como un espacio dispuesto a la negociación con dicha élite nacional. Su incorporación oficial a las listas del peronismo no ocurrió sino hasta 2007, sin embargo, durante esos años la táctica que este polo organizacional estructuró se basó en sostener un arraigo local y autonomía relativa, ${ }^{12}$ trazando un discurso de intervención pública bifronte — peronista y vecinalista - con el que, además de sustraerse de la disputa nacional, se constituyó en un espacio receptivo para la incorporación de grupos de base que quedaron golpeados en uno y otro bando.

Para 2007 este espacio había logrado un marco de alianzas amplio, atrayendo a organizaciones de envergadura nacional, como el Movimiento Evita, $^{13}$ otros con articulaciones provinciales, como los integrados en la Juventud Peronista provincial, y grupos extraparidarios que dotaban su frente de una imagen de pluralidad política. La estrategia provincial del Frente para la Victoria (FPV) de habilitar las listas colectoras ${ }^{14}$ les permitió participar del

\footnotetext{
${ }^{10}$ A partir de 2003 este grupo logró convocar a un conjunto muy heterogéneo de actores locales de diferentes extracciones: sectores del Frente Grande, del socialismo, del radicalismo, del partido Acción por la República y del peronismo que se sentían desplazados por las estrategias del peronismo oficial. ${ }^{11}$ Para un estudio de las diferentes estrategias del kirchnerismo, véase Martín Retamozo y Lucía Trujillo (2019).

${ }^{12}$ Incluso en 2005, cuando se produjo en la Provincia de Buenos Aires una fuerte disputa entre élites políticas nacionales: por un lado, el kirchnerismo y, por otro, el denominado duhaldismo (Calvo, 2005). ${ }^{13}$ Para un estudio del Movimiento Evita, véase Mauricio Schuttenberg (2014) y Francisco Longa (2019).

${ }^{14}$ Las «listas colectoras» conforman una táctica electoral por la cual las autoridades jurídicas partidarias habilitan a que en un mismo distrito - municipal o provincial— puedan coexistir dos o más listas de candidatos que aporten votos para el mismo espacio. Utilizada en diferentes ocasiones, esta táctica permite la competencia local en elecciones generales $\sin$ ir en detrimento de las candidaturas nacionales.
} 
espacio con la candidata nacional a la presidencia Cristina Fernández de Kirchner (CFK) y obtener una ajustada victoria sobre la lista oficial. La élite local que gobernaba municipio y partido político, encabezada por Julio Alak, fue desplazada y asumió como intendente Pablo Bruera por el FRP.

A los pocos meses de la asunción de CFK se suscitó un conflicto con las entidades empresariales agropecuarias que marcó el ritmo de la política argentina (Hora, 2010). El FRP se sumó a la estrategia nacional del FPV en un campo político dividido binariamente y se abrió un escenario complejo para este espacio que llevaba poco tiempo en la construcción de la hegemonía local. El problema sobrevino en las elecciones legislativas de 2009 —en simultáneo, nacionales, provinciales y locales-, en el que se vaticinaba una baja en la performance electoral del FPV en la Provincia de Buenos Aires. En dicha ocasión, el FRP optó por una táctica electoral fuertemente anclada en lo local y con visos de acumulación de votos por fuera de la boleta del FPV, apostando al corte de boletas. ${ }^{15}$ Este movimiento significó un conjunto de tensiones y desconfianzas con la élite nacional del FPV —el kirchnerismo— que no terminarían de saldarse nunca. Aun cuando esta situación no escaló hasta una ruptura definitiva, generó discusiones que terminaron con la salida de varios de los grupos aliados al FRP con mayor identificación hacia el kirchnerismo.

De las escisiones más significativas, por el volumen y los recursos propios, se destacan los casos del Movimiento Evita, el cual se desplazó del marco de alianzas a costa de una fractura interna por la cual un sector, denominado Agrupación Evita, quedó vinculado al FRP; y el caso de La Cámpora, ${ }^{16}$ la cual, aun con poca trayectoria dentro del distrito, contaba en ese momento con una ligazón directa con la élite nacional. Estas dos agrupaciones, junto con el entonces minoritario sector del alakismo —Frente Amplio Peronista- y un conjunto de organizaciones de base — territoriales, culturales y sindicales-, constituyeron un nuevo espacio de disputa electoral que primero llevó el nombre de Frente Social de la Provincia de Buenos Aires y luego se denominó Unidos y Organizados (UyO). Con mayor identificación con el kirchnerismo, este sector buscó construir una referencia de representación de las élites

\footnotetext{
${ }^{15}$ Los resultados electorales fueron muy elocuentes al respecto: en La Plata el FPV obtuvo 21,34\% de los votos válidos (65 564), quedando tercero en esta categoría; mientras que el FRP en el ámbito local obtuvo 34,53\% (108 258) de los votos válidos.

${ }^{16}$ Organización identificada fuertemente con el kirchnerismo. Fue formada hacia 2008 por jóvenes militantes peronistas ligados al gobierno de CFK. En poco tiempo logró un significativo desarrollo político, alcance territorial y caudal de militancia juvenil.
} 
El peronismo y la ciudad. Competencia y articulación en las estrategias electorales...

nacionales inscriptas en un ámbito local, pero a partir de amalgamar «desde abajo hacia arriba» expresiones existentes en el campo peronista platense.

La respuesta del Gobierno nacional ante la derrota parlamentaria en torno a la Resolución 125 y el revés electoral de 2009, fue un conjunto de medidas de alto impacto político que recompusieron la competitividad electoral para 2011, ${ }^{17}$ al punto de obtener el peronismo su mejor performance electoral — principal y nacional_ en lo que va del siglo. En La Plata, el FPV nacional alcanzó 43,53\% de votos válidos para Presidente (151 514), mientras que para Intendente el FRP alcanzó 44,75\% de votos (156 168) y la lista del Frente Social obtuvo 8,73\% (30 473) de los votos válidos. Una vez más, se observó que el FRP capturaba votos por fuera del esquema del FPV.

Entre 2012 y 2015 fueron consolidándose dos polos de representación política local: el FRP y UyO. ${ }^{18}$ La coyuntura electoral de 2013 encontró al kirchnerismo nacional con una pérdida de las expectativas electorales. La conformación del Frente Renovador con Sergio Massa a la cabeza, como ruptura del peronismo en el ámbito nacional con fuerte atractivo electoral, cambió las estructuras de oportunidad electoral para las agrupaciones locales. El FRP — que no tenía vínculos orgánicos con el Frente Renovador de Massaoptó por una táctica de retorno al vecinalismo y una alianza con el candidato del peronismo bonaerense, Martín Insaurralde (Annunziata, 2015). El otro nucleamiento - UyO — tuvo una relación mucho más estrecha con la élite nacional, incluso canalizando la intervención sobre la inundación de abril de 2013 (Escobar y Prósperi, 2014) por vías ligadas a las organizaciones locales y, especialmente, con la Facultad de Periodismo y Comunicación Social de la Universidad Nacional de La Plata. Finalmente, un grupo de dirigentes peronistas de menor relevancia y desarrollo vieron una ventana de oportunidades para transformarse en referentes del Frente Renovador de Sergio Massa en La Plata y capitalizar un efecto tracción por parte del candidato a diputado nacional que, finalmente, resultó vencedor. El vínculo con un espacio de conformación

\footnotetext{
${ }^{17}$ Solo por nombrar algunas de ellas, la Ley de servicios de Comunicación Audiovisual (2009), la implementación de la Asignación Universal por Hijo (AUH) (2009) y la Ley de Matrimonio Igualitario (2010) conformaron, junto a otras medidas, una batería de acciones que le permitieron al FPV nacional retomar la iniciativa y consolidar una identidad política: había nacido el kirchnerismo. Todo esto, sumado a los efectos simbólicos del fallecimiento del expresidente Néstor Kirchner, compuso un escenario donde el FPV protagonizó su mayor performance electoral.

${ }^{18}$ En abril de 2012 un conjunto de agrupaciones lanzó a escala nacional Unidos y Organizados como un intento de articulación de las organizaciones kirchneristas en momentos de una disputa interna y la aparición de movilizaciones opositoras.
} 
nacional, surgido como salida del peronismo, permitió a actores con pocos recursos tener una presencia electoral considerable. Esto se manifestó en las elecciones de 2013, 2015 y 2017.

Un dato central de esta elección fue que se consolidó en términos agonísticos la relación entre estas dos formas de representación política. Si en 2011 la expresión electoral de UyO pareció más una aventura que un proyecto concreto, en 2013, con la incorporación de la figura de Florencia Saintout como referente del espacio, más la construcción de una fuerte disputa con el intendente del FRP, Pablo Bruera, por sus respuestas frente a las inundaciones, mostraron que la relación de disputa sería intensa y explícita. Mientras el FRP se mantenía al frente del gobierno de la ciudad, UyO debía establecer una relación adversarial con esa fuerza, incrementando las críticas a la gestión y obviando espacios comunes de representación orgánica e identitaria.

La elección de 2015 tuvo como dato importante el desplazamiento de dicha disputa a una competencia interna entre ambos en las Primarias Abiertas Simultáneas y Obligatorias (PASO) (Gallo, 2017). Cada nucleamiento planteó una búsqueda de alianza con élites provinciales y nacionales y una táctica electoral propias. La cercanía del FRP con el candidato a presidente

[246] -y por entonces gobernador-, Daniel Scioli, le permitía proyectar una alianza extralocal de tipo poskirchnerista, obteniendo 18,3\% (70 187 votos), mientras el núcleo de UyO buscó una fidelización de la identidad particular del kirchnerismo en la permanente mención de la figura de CFK, obteniendo 14,92\% (57237 votos). El Frente Renovador de Sergio Massa tuvo un desempeño acotado en el ámbito nacional y en La Plata alcanzó un escaso $17 \%$ de votos válidos.

La derrota electoral del peronismo en los ámbitos local, provincial y nacional implicó un nuevo contexto y una reconfiguración de este espacio en la ciudad de La Plata, el cual se analizará a continuación (Retamozo y Schuttenberg, 2016).

\section{Las elecciones de 2017. Lealtad, voz y salida ${ }^{19}$}

Los cambios, luego de la derrota, se pueden apreciar fundamentalmente en dos dimensiones: por un lado, los nucleamientos se acercaron y trazaron

${ }^{19}$ Se tomó como base la célebre obra de Albert Hirschman (1977) para este apartado. 
El peronismo y la ciudad. Competencia y articulación en las estrategias electorales...

acuerdos comunes, posibilitados por la exclusión de la candidatura de Pablo Bruera, por la salida del marco de alianzas de UyO del espacio del Movimiento Evita y por el relego de posiciones «expectantes» de La Cámpora. Se trató de una confluencia con costos para ambos sectores, pero que permitió procesar la derrota y reconfigurar el espacio peronista a partir de una nueva frontera antagónica. Por otro lado, un conjunto de agrupaciones que habían surgido al calor del proceso electoral de 2015 encontró espacio y posibilidad de trazar estrategias de acumulación propias, especialmente a partir del activismo en redes y acciones de protesta ante la política del Gobierno nacional.

Sin embargo, el funcionamiento como oposición en los tres ámbitos también abrió una disputa por la hegemonía del peronismo en la nueva coyuntura. Básicamente, las posiciones se pueden identificar por la referencia al lugar del kirchnerismo como vector de la nueva fase - pos-2015- o el kirchnerismo como etapa superada. En efecto, a pesar de no ocupar ningún lugar institucional, la figura de CFK permaneció en el centro de la escena política y, con las elecciones legislativas en el horizonte, su nombre era el único que avizoraba un piso alto de votos en la provincia de Buenos Aires. Esta situación marcó el ritmo de la competencia entre los diferentes grupos en un campo habitado por actores debilitados —el FRP—, consolidados UyO- y nuevas expresiones locales que surgieron o se reactivaron en la coyuntura electoral de 2015.

La decisión de CFK hacia 2017 de armar un nuevo espacio —Unidad Ciudadana (UC)—, que prescindió del sello partidario formal, pero que incluyó a los principales referentes del peronismo provincial y la gran mayoría de intendentes peronistas, marcó el escenario (Retamozo y Trujillo, 2019). Esta situación potenció el poder de UyO, cuyo capital —la lealtad a CFK— facilitó su lugar de articulador de otras agrupaciones. La decisión de no competir con otras fuerzas en las PASO que tomó CFK en el ámbito provincial se reflejó en lo local; sin embargo, al no existir una figura indiscutible, la tensión sobre los lugares a ocupar incrementó la centralidad de una ingeniería por armar una boleta que contuviera a las múltiples agrupaciones. La lista de los candidatos a los cargos de representación local - tanto a concejales como a diputados provinciales - mostró la pluralidad de actores y el equilibrio alcanzado (véanse cuadros 1 y 2). 
Cuadro 1. Candidatos a diputados provinciales de Unidad Ciudadana (2017).

\begin{tabular}{|l|l|}
\hline \multicolumn{1}{|c|}{ Candidatos } & \multicolumn{1}{c|}{ Organización } \\
\hline Florencia Saintout & Unidos y Organizados (Frente) \\
\hline Guillermo Escudero & Frente Renovador Platense (FRP)-Frente para la Victoria (FPV) \\
\hline Mirta Mariño & $\begin{array}{l}\text { Sindicato de Obreros y Empleados de Minoridad y Educación } \\
\text { (SOEME) }\end{array}$ \\
\hline Juan Nieves & Unión de Personal Civil de la Nación (UPCN) \\
\hline Elsa Huwiler & Soberanía Nacional \\
\hline Jorge Luis Carpinetti & La Columna Alberti \\
\hline
\end{tabular}

Fuente: elaboración propia a partir de las boletas

Cuadro 2. Candidatos a concejales de Unidad Ciudadana. ${ }^{20}$

\begin{tabular}{|l|l|}
\hline \multicolumn{1}{|c|}{ Nombre } & \multicolumn{1}{c|}{ Agrupación } \\
\hline Victoria Tolosa Paz & Casa Para la Victoria Peronista \\
\hline Aníbal Norberto Gómez & Frente Amplio Peronista \\
\hline Ana Castagneto & Kolina \\
\hline Cristian Vander & $\begin{array}{l}\text { Sindicato de Obreros, Especialistas y Empleados de los } \\
\text { Servicios e Industria de las telecomunicaciones (SOEESIT) } \\
\text { de La Plata }\end{array}$ \\
\hline Alejandra Marcela López & $\begin{array}{l}\text { Frente Renovador Platense (FRP)-Frente para la Victoria } \\
\text { (FPV) }\end{array}$ \\
\hline Oscar Blanco & Por los Principios Sociales \\
\hline Julia Lucía Di Jorgi & Peronismo Militante \\
\hline Alberto Ramón Ramírez & Frente Político y Social Carlos Cajade \\
\hline Sabrina Noemí Rodríguez & Los Apóstoles de Perón \\
\hline Jorge Ignacio Malpeli & Vuelta de Obligado \\
\hline Gabriela Chaparro & La Walsh \\
\hline Ángel Clemente Ibáñez & John William Cooke \\
\hline
\end{tabular}

Fuente: elaboración propia.

En la arquitectónica de las listas es posible observar algunos puntos centrales: en primer lugar, la lista de UC fue construida de modo articulado entre las categorías de diputados provinciales y concejales, de tal modo que 
El peronismo y la ciudad. Competencia y articulación en las estrategias electorales...

la distribución de lugares expectantes ${ }^{21}$ fue realizada de forma inclusiva entre diversas agrupaciones, impidiendo que alguna de ellas ocupara dos lugares a la vez; en segundo lugar, el criterio de organización estuvo lejos de replicar el histórico criterio de tercios ${ }^{22}$ o el criterio de centro periferia que se adoptó en la década de $1990 .{ }^{23}$ En esta ocasión, el criterio podría definirse como corpuscular, construyendo una suerte de equilibrio en la dispersión de agrupamientos de base. Como se podrá observar a continuación, este mismo criterio primó para el armado de la lista del frente Cumplir (véase cuadros 3 y 4).

Cuadro 3. Candidatos a diputados provinciales, Lista 2 Alianza Cumplir.

\begin{tabular}{|l|l|}
\hline \multicolumn{1}{|c|}{ Nombre } & \multicolumn{1}{c|}{ Agrupación } \\
\hline Gustavo Di Marzio & Movimiento Evita \\
\hline Norma Antonia Benitez & Ateneo Eva Perón \\
\hline Roberto Daniel Prandini & Ateneo Eva Perón \\
\hline
\end{tabular}

Fuente: elaboración propia.

Cuadro 4. Candidatos a concejales, Lista 2 Alianza Cumplir.

\begin{tabular}{|l|l|}
\hline \multicolumn{1}{|c|}{ Nombre } & \multicolumn{1}{c|}{ Agrupación } \\
\hline Paula Lambertini & Agrupación Evita \\
\hline Diego Fernández Camillo & Movimiento Evita \\
\hline Gudalaupe Reboredo & Corriente Nacional Popular Latinoamericana (Conapla) \\
\hline Ramón Galache & La Cafiero \\
\hline
\end{tabular}

Fuente: elaboración propia.

Un dato sobresaliente de estas listas de candidatos estriba en los importantes lugares obtenidos por las agrupaciones con menor recorrido histórico en el distrito. Al respecto, tres casos pueden ser señalados como ejemplos: Casa Para la Victoria Peronista, Frente Político y Social Carlos Cajade y, en la lista de Cumplir — que competía con unidad Ciudadana-, la organización La Cafiero. Estas tres organizaciones surgieron al calor de la disputa electoral en 2015 y se asentaron en el distrito por medio de eventos multiorganizacionales que se produjeron hasta 2017. Muchos de estos eventos no contaron con la participación directa de las organizaciones con mayor trayectoria. La conjunción de estos eventos públicos y el cambio de escenario 
tras la derrota electoral, operaron como una ventana de oportunidades electorales para el rápido reconocimiento de estos grupos.

La «lealtad» a la conducción de la expresidenta fue un factor clave para la consolidación del polo liderado por Florencia Saintout, que le permitió articular «voces» nuevas —surgidas al calor de las movilizaciones de la coyuntura electoral de 2015-, así como viejas demandas de participación en el peronismo. Finalmente, la «salida» quedó para los actores que conformaron Cumplir, bajo el enmarcado de un inexorable agotamiento de la figura de CFK como referente central del peronismo. Ahora bien, las dos listas que se presentaron por esta alternativa en La Plata ${ }^{24}$ mostraron una arquitectónica también grupal, pero donde los cargos más «expectantes» fueron ocupados por las agrupaciones con mayor volumen político.

Un caso singular fue el del Frente Renovador (FR), liderado por Sergio Massa, que tras los magros resultados obtenidos en 2015 también ingresó en una curva descendente de su performance política. Esta situación, sumada a la alternativa del Frente Cumplir, estrechó el marco de alianzas posibles para esta fuerza. Las listas de este espacio las encabezaron como candidato a diputado provincial José Arteaga — proveniente del peronismo y fundador del FR en La Plata — y para concejal Gastón Crespo — proveniente del GENgracias al acuerdo provincial vigente. El desempeño electoral del peronismo puede apreciarse en la tabla 1.

El resultado de laselecciones legislativas 2017 tuvo efectos performativos en el campo político nacional y local. A pesar de haber quedado segunda en la elección general a senadores nacionales, la expresidenta CFK obtuvo una significativa diferencia con los otros dos candidatos peronistas - Sergio Massa, del Frente Renovador, y Florencio Randazzo de PJ-Cumplir-. Con esto puso en evidencia el caudal electoral y la capacidad de articulación del kirchnerismo por sobre los otros espacios, y también sus limitaciones. En el ámbito local, los resultados acompañaron las cifras provinciales y mostraron la inviabilidad competitiva de opciones «pos-kirchneristas», a la vez que las mismas limitantes que el armado de CFK en el ámbito nacional.

\footnotetext{
${ }^{24}$ Por cuestión de espacio solo se presenta la lista de candidatos del Frente Cumplir que ganó las PASO. En la lista 4, la oponente, es de destacar el lugar de primer candidato a concejal que ocupó Federico Martelli, quien fuera referente del Movimiento de Unidad Popular (MUP) (Schuttenberg, 2014) y que entre 2007 y 2015 estuvo ligado al FRP.
} 
El peronismo y la ciudad. Competencia y articulación en las estrategias electorales...

Tabla 1. Resultados electorales 2017, La Plata. Octava sección electoral.

\begin{tabular}{|c|c|c|c|c|}
\hline \multirow[t]{2}{*}{ Fuerza } & \multicolumn{2}{|c|}{$\begin{array}{c}\text { Primarias Abiertas } \\
\text { Simultáneas } \\
\text { y Obligatorias }\end{array}$} & \multicolumn{2}{|c|}{ Generales } \\
\hline & Votos & $\%$ & Votos & $\%$ \\
\hline Cambiemos Buenos Aires & 161877 & 41,3 & 199525 & 47,22 \\
\hline Unidad Ciudadana & 95797 & 24,28 & 109732 & 25,97 \\
\hline Frente Justicialista & 28672 & 7,27 & \multirow{3}{*}{25168} & \multirow{3}{*}{5,55} \\
\hline Lista Cumplir 2 & 15887 & 55,41 & & \\
\hline Lista Cumplir 4 & 11063 & 38,58 & & \\
\hline Alianza 1 País & 48957 & 12,4 & 37266 & 8,82 \\
\hline $\begin{array}{l}\text { Frente de Izquierda y de los } \\
\text { Trabajadores (FIT) }\end{array}$ & 19503 & 4,94 & 26047 & 6,16 \\
\hline Vamos Creando Ciudad Nueva & 8388 & 2,13 & 9674 & 2,29 \\
\hline Izquierda al Frente por el Socialismo & 6416 & 1,63 & 3509 & 0,83 \\
\hline $\begin{array}{l}\text { Corriente de Pensamiento Bonaerense } \\
\text { (Co.Pe.Bo) }\end{array}$ & 5748 & 1,46 & - & - \\
\hline Partido Federal & 4382 & 1,1 & - & - \\
\hline Partido Socialista & 4102 & 1,04 & - & - \\
\hline Alianza Frente Unión Federal & 2179 & 0,54 & - & - \\
\hline Partido Renovador Federal & 1994 & 0,51 & - & - \\
\hline Unión Vecinalista Platense & 899 & 0,23 & - & - \\
\hline Partido Todos por Buenos Aires & 1166 & 0,3 & - & - \\
\hline $\begin{array}{l}\text { Encuentro Popular por Tierra, Techo } \\
\text { y Trabajo }\end{array}$ & 797 & 0,2 & - & - \\
\hline Total & 410758 & 77,09 & 422514 & 79,3 \\
\hline
\end{tabular}

Fuente: elaboración propia a partir de Junta Electoral (s. f.). 


\section{Elecciones 2019: «Todos unidos triunfaremos»}

En 2019 el contexto económico y el desgaste del oficialismo, por un lado, y las estrategias de armado político del peronismo en el ámbito nacional de tipo aperturista, por el otro, influyeron en el cambio de estructura de oportunidades electorales. Los recursos construidos —como candidaturas competitivas y de alto conocimiento- y una pluralidad de agrupaciones consolidadas fueron un potencial de movilización electoral significativo. La cuestión de cómo procesar ese caudal de movilización en una oferta electoral que contuviera a los diferentes actores se constituyó en un tema central. Aquí, a diferencia de lo sucedido en el ámbito nacional y provincial, en el que no hubo competencia interna, las PASO sirvieron para dirimir el armado de las listas, a la vez que significó una ampliación del espacio de convocatoria.

La consecuencia fue la apertura a la participación de cinco listas: la primera, con La Cámpora, el Movimiento Evita, referentes del Frente Renovador — de Massa- y un conjunto de agrupaciones que provenían del marco de alianzas de UyO previo, liderada por Florencia Saintout; la segunda opción, constituida por un conjunto de nuevas agrupaciones,

[252] escisiones de La Cámpora y otros espacios, encabezado por Victoria Tolosa Paz; la tercera opción, más vinculada al viejo FRP y una alianza con sectores sindicales antes opositores al FPV; la cuarta opción, con agrupaciones de base estudiantil que no presentaban una trayectoria en el peronismo local, pero que en 2017 habían convocado a votar por la expresidenta CFK, entramado que encontró en Luis Arias — exjuez que tomó notoriedad por su desempeño luego de las inundaciones de 2013 - un candidato con cierta instalación en la opinión pública; y finalmente, la quinta opción, constituida principalmente por el Movimiento Unidad Popular (MUP), una agrupación que en 2017 participó en Cumplir.

Cuadro 5. Intendente, Lista celeste y blanca 4.

\begin{tabular}{|l|l|}
\hline \multicolumn{1}{|c|}{ Nombre } & \multicolumn{1}{c|}{ Agrupación } \\
\hline Florencia Saintout & La Walsh \\
\hline \multicolumn{2}{|c|}{ Concejales Lista celeste y blanca 4 } \\
\hline Ariel Archanco & La Cámpora \\
\hline Yanina Andrea Lamberti & Diex \\
\hline Facundo Mario Albini & Frente Renovador \\
\hline
\end{tabular}

Fuente: elaboración propia a partir de las boletas oficiales. 
El peronismo y la ciudad. Competencia y articulación en las estrategias electorales...

Cuadro 6. Intendente, Lista celeste y blanca 6.

\begin{tabular}{|c|c|}
\hline Nombre & Agrupación \\
\hline Luis Federico Arias & Extrapartidario \\
\hline \multicolumn{2}{|c|}{ Concejales Lista celeste y blanca 6} \\
\hline Leandro Tomás Amoretti & Frente Patria Grande \\
\hline Claudia Mabel Corrales & Movimiento Justicia y Libertad \\
\hline Emilio Fernando López Muntane & Agrupación Joaquín Arieta \\
\hline
\end{tabular}

Fuente: elaboración propia a partir de las boletas oficiales.

Cuadro 7. Intendente, Lista celeste y blanca 8.

\begin{tabular}{|l|l|}
\hline \multicolumn{1}{|c|}{ Nombre } & \multicolumn{1}{c|}{ Agrupación } \\
\hline Victoria Tolosa Paz & Casa Para La Victoria Peronista \\
\hline \multicolumn{2}{|c|}{ Concejales Lista celeste y blanca 8} \\
\hline Cara Guillermo «Nano» & La Jauretche \\
\hline María Alejandra Wagner & La 17 de Octubre \\
\hline Miguel Ángel Forte & Sindicato de Choferes de Camiones \\
\hline
\end{tabular}

Fuente: elaboración propia a partir de las boletas oficiales.

Cuadro 8. Intendente, Lista celeste y blanca 10.

\begin{tabular}{|c|c|}
\hline Nombre & Agrupación \\
\hline Federico Martelli & Movimiento Unidad Popular (MUP) \\
\hline \multicolumn{2}{|c|}{ Concejales Lista celeste y blanca 10} \\
\hline Marisol Aranguren & Movimiento Unidad Popular (MUP) \\
\hline Enrique Mauricio Nicolini & Juventud Evangélica La Plata \\
\hline Sabrina Noemí Rodríguez & Los Apóstoles de Perón \\
\hline
\end{tabular}

Fuente: elaboración propia a partir de las boletas oficiales.

Cuadro 9. Intendente, Lista celeste y blanca 12.

\begin{tabular}{|l|l|}
\hline \multicolumn{1}{|c|}{ Nombre } & \multicolumn{1}{c|}{ Agrupación } \\
\hline Guillermo Martín Escudero & Frente Renovador Platense (FRP) \\
\hline \multicolumn{2}{|c|}{ Concejales Lista celeste y blanca 12 } \\
\hline Gastón Harispe & Octubres \\
\hline Yanina Gisela Sánchez & Asociación Trabajadores del Estado (ATE) \\
\hline Hugo Ernesto Romero & Frente Renovador Platense (FRP) \\
\hline
\end{tabular}

Fuente: elaboración propia a partir de las boletas oficiales. 
La apertura para la competencia interna en la ciudad significó mucho más que un cambio táctico en el juego electoral. Respecto de las relaciones intraorganizacionales, se trató de un aliciente para las negociaciones asimétricas entre las élites nacionales y provinciales con los actores locales. En primer lugar, la élite obtuvo la ganancia de poder establecer un punto de encaje común a todas las propuestas, lo cual se observó en la presentación de una única lista de senadores provinciales, así una posible dispersión de las preferencias electorales se concentraría en una única categoría de la boleta; ${ }^{25}$ por otro lado, para los polos agrupacionales locales la apertura significó la distensión de la disputa por los espacios expectantes, lo que permitió una campaña electoral mucho más ordenada y sin enfrentamientos significativos. ${ }^{26}$

La lista ganadora de las PASO fue la número 4, este espacio logró articular un marco de alianzas más amplio que el de las otras fuerzas. Es importante remarcar, además, que esta candidata había trazado en sus participaciones electorales anteriores un perfil de intervención hacia el electorado de fidelización con la figura de la expresidenta CFK, lo que le permitía contar con un voto duro como piso.

El triunfo de la lista encabezada por Florencia Saintout por escaso margen la consagró como candidata a intendenta en un contexto en el que el Frente de Todos obtuvo una clara ventaja sobre el oficialismo de Juntos por el Cambio. A partir del resultado y el acuerdo para la distribución de cargos, interno al Frente de Todos (s. f.), se sumaron a la lista de concejales en los puestos 5 y 10 los candidatos de la minoría (Lista 8) y ninguno proveniente de las otras tres listas. Sin embargo, en las elecciones generales Saintout no pudo retener todo ese caudal de votos — 171 830 (40,76\%) y fue derrotada por Julio Garro, que incrementó en más de cincuenta mil votos su performance.

\footnotetext{
${ }^{25}$ El resultado electoral muestra datos interesantes en esta categoría: en las PASO obtuvo 178993 votos $(44,25 \%), 7900$ votos menos que en la categoría municipal de todas las listas sumadas. Pero en el recuento provisorio de las elecciones generales esta categoría alcanzó 181380 votos (43,13\%), superando por casi diez mil votos a la categoría municipal (Junta Electoral, s. f.).

${ }^{26}$ Luego de las elecciones primarias, los candidatos de los cinco espacios protagonizaron varias actividades de campaña en conjunto (Junta Electoral, s. f.).
} 
El peronismo y la ciudad. Competencia y articulación en las estrategias electorales...

Tabla 2. Resultados electorales 2019, La Plata. Octava sección electoral.

\begin{tabular}{|c|c|c|c|c|}
\hline \multirow[t]{2}{*}{ Fuerza } & \multicolumn{2}{|c|}{$\begin{array}{c}\text { Primarias Abiertas } \\
\text { Simultáneas y } \\
\text { Obligatorias }\end{array}$} & \multicolumn{2}{|c|}{ Generales $^{27}$} \\
\hline & Votos & $\%$ & Votos & $\%$ \\
\hline Juntos por el Cambio & 155729 & 37,06 & 205367 & 48,72 \\
\hline Frente de Todos & 198598 & 47,26 & \multirow{6}{*}{171830} & \multirow{6}{*}{40,76} \\
\hline Lista celeste y blanca 4 & 62056 & 31,25 & & \\
\hline Lista celeste y blanca 8 & 60487 & 30,46 & & \\
\hline Lista celeste y blanca 12 & 33183 & 16,71 & & \\
\hline Lista celeste y blanca 6 & 31155 & 15,69 & & \\
\hline Lista celeste y blanca 10 & 11717 & 5,9 & & \\
\hline Consenso Federal & 27599 & 6,57 & 21431 & 5,08 \\
\hline $\begin{array}{l}\text { Frente de Izquierda y de los Trabajadores } \\
\text { (FIT) }\end{array}$ & 17753 & 4,22 & 17573 & 4,16 \\
\hline Frente Nos & 7338 & 1,75 & 5287 & 1,25 \\
\hline Partido Dignidad Popular & 755 & 0,18 & - & - \\
\hline Movimiento Avanzada Socialista & 4385 & 1,04 & - & - \\
\hline Frente Patriota & 1101 & 0,26 & - & - \\
\hline Partido Humanista & 1133 & 0,27 & - & - \\
\hline Movimiento de Organización Democrática & 2622 & 0,62 & - & - \\
\hline Alternativa Vecinal Platense & 3193 & 0,76 & - & - \\
\hline Total & 444629 & 75,68 & 442165 & 75,26 \\
\hline
\end{tabular}

Fuente: elaboración propia a partir de Junta Electoral (s. f.).

\section{Conclusiones}

En este artículo se ha ofrecido una reconstrucción de la dinámica política del peronismo en la ciudad de La Plata. El estudio de las coyunturas electorales permitió indagar en un momento en el que las correlaciones de fuerzas se cristalizan y en el que una mirada analítica puede reconstruir y explicar las estrategias del peronismo. La estrategia, como resultante de

${ }^{27}$ Los datos de esta columna son provisorios, pues aún falta el escrutinio definitivo. De todas formas, los actores han reconocido las victorias y las derrotas en cada espacio (Junta Electoral, s. f.). 
la interacción entre tácticas relativamente autónomas-locales, estructura de oportunidades electorales y vetos de las élites partidarias, configura una forma de «movilización partidaria» del peronismo que encuentra en el diseño electoral oportunidades y límites para resolver sus disputas. En efecto, el modo de distribuir las candidaturas en las distintas categorías -Ejecutivo, Legislativo local y provincial_ o de resolver la oferta para las generales luego de primarias competitivas marcaron condiciones de posibilidad distintos. Por su parte, la noción de «movilización partidaria» ayuda a pensar la interacción entre la lógica del movimiento y la lógica del partido presente en el peronismo platense.

En los eventos electorales de 2017 y 2019, con el peronismo en la oposición, se pudo mostrar los modos en que se construyó la unidad con dos estrategias finales disímiles. En 2017, en parte porque las elecciones fueron legislativas, el peronismo consiguió una lista de unidad entre los dos núcleos consolidados y la novedad fue la aparición de un tercer polo en torno a la figura de Victoria Tolosa Paz. Sin embargo, cabe mencionar que por fuera de esa lista se presentaron tres opciones electorales que en 2019 confluyeron en el Frente de Todos: Cumplir, Frente Renovador (1Pais) y Vamos Creando Ciudad Nueva. Esta estrategia tuvo la virtud de ofrecer incentivos a las fuerzas para la movilización, ya que del buen desempeño de la lista dependía el acceso a cargos electivos para los diferentes sectores.

En 2019 el escenario fue diferente. En primer lugar, porque la elección ejecutiva definía perspectivas de liderazgo del espacio político; en segundo lugar, porque la trama de unidad producida desde «arriba hacia abajo» tensionó la capacidad de las listas de contener a todos los sectores con aspiraciones. A los tres agrupamientos centrales - Frente Renovador Platense, el espacio de Florencia Saintout y el de Victoria Tolosa Paz- se sumaron los provenientes de Cumplir, Frente Renovador de Sergio Massa y Patria Grande. Esto generó dos situaciones: por un lado, excepto la incorporación del FR-Massa al espacio de Saintout, no existieron expansiones en el marco de alianzas, la consecuencia fue la existencia de cinco listas disputando las PASO; por otro lado, el diseño del «acuerdo» por el que repartieron los cargos fue del tipo «ganador lleva todo». En efecto, luego del ajustado triunfo de Saintout el resto de los contendientes en las primarias tuvieron pocos lugares seguros y casi ninguno expectante, con lo que se desincentivó su involucramiento en la campaña electoral. Así, el Frente de Todos obtuvo en las PASO de 2019 una cantidad similar a la suma de las partes de 2017. Esta cantidad, que 
El peronismo y la ciudad. Competencia y articulación en las estrategias electorales...

supuso 10\% más que su adversario, mermó en las elecciones generales y la fuerza oficialista —en una estrategia de vecinalización- logró incrementar su caudal de votos y se alzó con el triunfo electoral.

El análisis de las dinámicas políticas del peronismo de la ciudad de La Plata muestra su dimensión como movimiento partidario. La lógica del movimiento es la que pone en escena a una variedad de organizaciones de base, en muchos casos autónomas, desafiliadas del propio partido, ligadas de diferente modo al peronismo como tradición e identidad política. Estas organizaciones —sindicales, culturales, barriales, estudiantiles, entre otros - confluyen en una especie de regularidad en la dispersión y se articulan con mayor visibilidad en los momentos electorales. En efecto, las elecciones requieren de un comportamiento, fundamentalmente bajo la lógica de un partido político como actor del sistema electoral. Allí la estrategia local no se derivó mecánicamente de lo nacional o provincial, sino que fue resultante de tácticas de actores locales en el marco de estructuras de oportunidades electorales — formales e informales_- En el caso estudiado, la multiplicidad de organizaciones de base provocó una expansión y la posibilidad de encarnar demandas, pero también una dificultad para procesar esta heterogeneidad en el armado de instrumentos electorales eficientes y eficaces para contender. En este sentido es que el diseño de la estrategia electoral —el modo de repartir las candidaturas y definir las listas luego de las primarias - generó un dilema para la fuerza política de cara a las elecciones generales de 2019. El peronismo, en el caso platense, muestra la dinámica del denominado «movimiento partidario», producto de la lógica del movimiento político que permite la aparición y expansión de organizaciones de base y una lógica de partido político que requiere de formas más centralizadas e instituidas para guiar la acción. Estos momentos se articulan de diferente manera, de acuerdo a la temporalidad política y a la ubicación de la fuerza en el sistema político, ya sea gobierno u oposición.

Los resultados de la contienda electoral de 2019 produjeron resultados victoriosos para el Frente de Todos en los ámbitos nacional y provincial, sin embargo, en la ciudad de La Plata el triunfo fue para la Alianza Cambiemos. Indagar en la dinámica política local en este contexto novedoso, tanto en tiempos de «movimiento» — ahora también marcados por el Covid-19_, como en las próximas coyunturas electorales, será objeto de futuras investigaciones. 


\section{Referencias bibliográficas}

1. Aboy Carlés, Gerardo. (2001). Las dos fronteras de la democracia argentina. La reformulación de las identidades políticas de Alfonsín a Menem. Buenos Aires: Homo Sapiens.

2. Aelo, Oscar H. (2006). Formación y crisis de una elite dirigente en el peronismo bonaerense 1946-1951. En: Melon Pirro, Julio C. y Quiroga, Nicolás (eds.). El peronismo bonaerense: partido y prácticas políticas, 1946-1955 (pp. 15-42). Mar del Plata: Suárez.

3. Altamirano, Carlos. (2001). Peronismo y cultura de izquierda. Buenos Aires: Temas.

4. Annunziata, Rocío. (2013). Una propuesta de clasificación de los dispositivos participativos en Argentina. Postdata, 18 (2), pp. 247-280.

5. Annunziata, Rocío (coord.). (2015). Liderazgos de proximidad y procesos electorales: Ios casos de Sergio Massa y Martín Insaurralde en las legislativas del 2013. En: Pensar las elecciones: democracia, líderes y ciudadanos (pp. 95-128). Buenos Aires: Clacso.

6. Argentina.gob.ar. (s. f.). Elecciones 2009. Recuperado de https://www. argentina.gob.ar/interior/dine/resultadosyestadisticas/2009

7. Barry, Carolina. (2009). Evita capitana: el partido peronista femenino, 19491955. Tres de Febrero: Eduntref.

8. Calvo, Ernesto. (2005). Argentina, elecciones legislativas 2005: consolidación institucional del kirchnerismo y territorialización del voto. Revista de Ciencia Política, 25 (2), pp. 153-160. https://doi.org/10.4067/S0718-090X2005000200007

9. Calvo, Ernesto. (2013). El peronismo y la sucesión permanente: mismos votos, distintas elites. Revista SAAP, 7 (2), pp. 433-440.

10. Calvo, Ernesto y Escolar, Marcelo. (2005). La nueva política de partidos en la Argentina: Crisis política, realineamientos partidarios y reforma electoral. Buenos Aires: Prometo.

11. Casullo, María Esperanza. (2015). Argentina: del bipartidismo a la democracia peronista. Nueva Sociedad, 258, pp. 16-28.

12. Casullo, María Esperanza. (2019). Por qué funciona el populismo. Buenos Aires: Siglo xxı.

13. Casullo, María Esperanza y Rodríguez, Santiago. (2015, junio 4). Apogeo y caída del Frente Renovador: un juego de mapas. El Estadista. Recuperado de http:// elestadista.com.ar/?p=7003

14. Di Tella, Torcuato. (1973). Populismo y reformismo. En: Germani, Gino; Di Tela, Torcuato y lanni, Octavio. Populismo y contradicciones de clase en argentina (pp. 38-82). México, D. F.: Era. 
El peronismo y la ciudad. Competencia y articulación en las estrategias electorales...

15. Eryszewicz, Leandro. (2015). ¿Localización de la política? El protagonismo de los intendentes argentinos en la escena nacional. En: Annunziata, Rocío (coord.). Pensar las elecciones: democracia, líderes y ciudadanos (pp. 61-94). Buenos Aires: Clacso.

16. Escobar, María Soledad y Prósperi, Gabriel. (2014). Inundados La Plata. Lo que el agua no encubrió. La Plata: EDULP.

17. Escolar, Marcelo; Calvo, Ernesto; Calcagno, Natalia y Minvielle, Sandra. (2002). Últimas imágenes antes del naufragio: las elecciones del 2001 en la Argentina. Desarrollo Económico, 42 (165), pp. 25-44. https://doi.org/10.2307/3455975

18. Ferrari, Marcela. (2016). La Provincia de Buenos Aires. En: Ferrari Marcela y Mellado, Virginia (comps.). La renovación peronista. Organización partidaria, liderazgos y dirigentes, 1983-1991. Buenos Aires: Eduntref.

19. Freidenberg, Flavia. (2006). La democratización de los partidos políticos en América Latina: entre la ilusión y el desencanto. En: Sánchez, Fernando y Thompson, Joseph (eds.). Fortalecimiento de los partidos políticos en América Latina: institucionalización, democratización y transparencia (pp. 91-141). San José de Costa Rica: Capel, Instituto Interamericano de Derechos Humanos.

20. Frente de Todos. (s. f.). Elecciones Provinciales 2019. Recuperado de https:// frentedetodos.org/juntaelectoral/buenosaires.html

21. Gallo, Aadriana. (2017). Un doble PASO electoral. Análisis del debut del sistema de primarias abiertas y de la vuelta doble electoral en las elecciones presidenciales argentinas de 2015. Studia Politicæ, 41, pp. 45-87. https://doi. org/10.22529/sp.2017.41.02

22. Garategaray, Martina. (2013). Entre Perón y Alfonsín: notas sobre la Renovación peronista (1983-1988). Temas y Debates, 25, pp. 35-37.

23. Germani, Gino. (1965). Política y sociedad en una época de transición. Buenos Aires: Paidós.

24. Hirschman, Albert. (1977). Salida, voz y lealtad. México, D. F.: FCE.

25. Hora, Roy. (2010). La crisis del campo del otoño 2008. Desarrollo Económico, 50 (197), pp. 81-111.

26. James, Daniel. (1990). Resistencia e integración. El peronismo y la clase trabajadora argentina. Buenos Aires: Siglo xxı.

27. Junta Electoral de la Provincia de Buenos Aires. (s. f.). Elecciones Generales del año 2009 - Distrito La Plata. Recuperado de http://www.juntaelectoral.gba.gov.ar/ distritoEstadisticasHistoricas.php?anio $=2009 \&$ did $=063$

28. Lenarduzzi, Julieta. (2012). «Permanecer y trasncurrir»: los discursos de la renovación política en la democracia argentina (1983-2011). [Tesis inédita de maestría]. Universidad Nacional de San Martín, Buenos Aires. Recuperado de http://ri.unsam.edu.ar/bitstream/handle/123456789/304/TMAG_IDAES_2012_ LJ.pdf? sequence $=1$ \&isAllowed $=y$ 
29. Levitsky, Steven. (2005). La transformación del Justicialismo: del partido sindical al partido clientelista: 1993-1999. Buenos Aires: Siglo Xxı.

30. Longa, Francisco. (2019). Historia del Movimiento Evita: La organización social que entró al Estado sin abandonar la calle. Buenos Aires: Siglo xxı.

31. Mackinnon, Maria Moira. (2002). Los años formativos del partido peronista (1946-1950). Buenos Aires: Siglo xxı.

32. Macor, Darío y Tcach, César. (2003). La invención del peronismo en el interior del país I. Santa Fe: Universidad Nacional del Litoral.

33. Macor, Darío y Tcach, César. (2013). La invención del peronismo en el interior del país II. Santa Fe: Universidad Nacional del Litoral.

34. Martuccelli, Danilo y Svampa, Maristella. (1997). La Plaza Vacía. Las transformaciones del peronismo. Buenos Aires: Losada.

35. Mauro, Sebastián; Ortiz de Rozas, Victoria y Paratz Vaca Narvaja, Martín (comps.). (2017). Política subnacional en Argentina. Enfoques y problemas. Buenos Aires: CEAP, UBA.

36. McAdam, Doug; Tarrow, Sidney y Tilly, Charles. (2005). Dinámica de la contienda política. Barcelona: Hacer.

37. Michels, Robert. (1979). Los partidos políticos. Buenos Aires: Amorrortu.

38. Montero, Ana Soledad. (2012). ¡Y al final un día volvimos! Los usos de la memoria en el discurso kirchnerista: 2003-2007. Buenos Aires: Prometeo.

39. Murmis, Miguel y Portantiero, Juan Carlos. (1969). Estudios sobre los orígenes [260] del peronismo. Buenos Aires: Siglo xxı.

40. Mustapic, Ana. (2002). Del partido peronista al partido justicialista. Las transformaciones de un partido carismático. En: Cavarozzi, Marcelo y Juan Manuel Abal Medina (h) (comps.). El asedio a la política. Los partidos latinoamericanos en la era neoliberal. Rosario: Homo Sapiens.

41. Mustapic, Ana. (2005). Inestabilidad sin colapso. La renuncia de los presidentes: Argentina en el año 2001. Desarrollo Económico, 45 (178), pp. 263-280.

42. Novaro, Marcos. (1999). Crisis y renovación de los partidos. Una perspectiva comparada sobre los años del menemismo. En: Torre, Juan Carlos; Novaro, Marcos; Palermo, Vicente y Cheresky, Isidoro. Entre el abismo y la ilusión. Peronismo, democracia y mercado. Buenos Aires: Norma.

43. Ollier, María Matilde. (2010). El liderazgo político en democracias de baja intitucionalización (el caso del peronismo en la Argentina). Revista de Sociología, 24, pp. 127-150. http://dx.doi.org/10.5354/0719-529X.2011.14409

44. Panebianco, Angelo. (1990). Modelos de partido. Madrid: Alianza.

45. Pérez, Germán y Natalucci, Ana. (2012). El kirchnerismo como problema sociológico. En: «Vamos las bandas». Organización y militancia kirchnerista. Buenos Aires: Nueva Trilce. 
El peronismo y la ciudad. Competencia y articulación en las estrategias electorales...

46. Rein, Raanan. (2008). Los hombres detrás del Hombre: la segunda línea de liderazgo peronista. Araucaria, 10 (19), pp. 78-92.

47. Retamozo, Martín y Schuttenberg, Mauricio. (2016). La política, los partidos y las elecciones en Argentina 2015: ¿hacia un cambio en el campo político? Análisis Político, 29 (86), pp. 113-140. https://doi.org/10.15446/anpol.v29n86.58046

48. Retamozo, Martín y Trujillo, Lucía. (2019). El kirchnerismo y sus estrategias políticas en Argentina: desde la transversalidad hasta Unidad Ciudadana. Izquierdas, 45. https://doi.org/10.4067/S0718-50492019000100185

49. Sartori, Giovanni. (1994). Partidos y sistemas de partidos. Marcos para un análisis. Madrid: Alianza.

50. Schuttenberg, Mauricio. (2014). Las identidades nacional-populares. De la resistencia noventista a los años kirchneristas. Villa María: Universidad Nacional de Villa María.

51. Tarrow, Sidney. (1997). El poder en movimiento. Madrid: Alianza.

52. Tcach, César. (2002). El enigma peronista: la lucha por su interpretación. Historia Social, 43, pp. 129-139.

53. Torre, Juan Carlos. (1999). El peronismo como solución y como problema. En: Torre, Juan Carlos; Novaro, Marcos; Palermo, Vicente y Cheresky, Isidoro. Entre el abismo y la ilusión. Peronismo, democracia y mercado. Buenos Aires: Norma.

54. Varetto, Carlos y Rotman, Santiago. (2017). Carreras y ambición política a nivel subnacional. Análisis de las carreras políticas de los intendentes en la provincia de Buenos Aires (Argentina), 1983-2015. Política, 55 (1), pp. 65-98. http://dx.doi. org/10.5354/0716-1077.2017.50790

55. Vilas, Carlos. (2004). Gobernabilidad democrática y heterogeneidad social: la crisis argentina de 2001. Revista SAAP, 1 (3), pp. 561-589. 